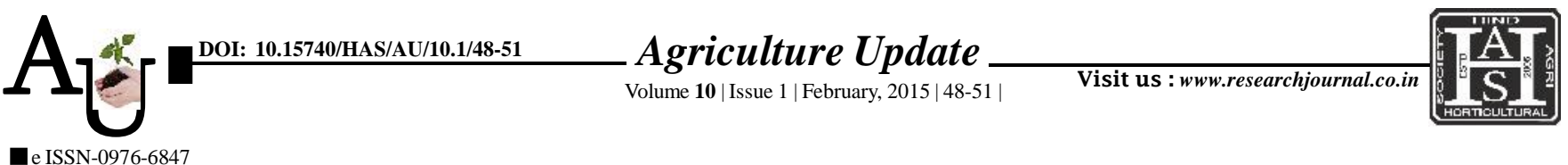

\title{
Research автіcle: Factors affecting the information seeking behaviour of the ber growers
}

Article Chronicle:

Received :

16.12.2014;

Revised :

07.01.2015;

Accepted :

21.01.2015
Key Words :

Information sources,

Ber growers, Variables

\section{B.L. DHAYAL, B.C. BOCHALYA* AND H.M. BHUVA}

SUMMARY : The present study was under taken in ber growing area of Rajasthan to know the information behaviour of ber growers. For the study 100 ber growers were selected by using random sampling method. Statistical analysis was done to inferences the result. it was observed that majority of ber growers were having medium level of information seeking behaviour. The association between the information seeking behaviour of ber growers and the selected independent variables viz., age, education level, social participation, size of land holding, farm power, family size, farming experience, innovation proneness and annual income of the ber growers were measured by computing co-efficient of correlation(r). It is revealed from the study that the ber growers education level, social participation, size of land holding, farm power, innovation proneness and annual income were found positively and significantly correlated with their information seeking behaviour at 0.01 level of probability, while the age of the ber growers was found negatively and significantly correlated with their information seeking behaviour at 0.05 level of probability.

How to cite this article : Dhayal, B.L., Bochalya, B.C. and Bhuva, H.M. (2015). Factors affecting the information seeking behaviour of the ber growers. Agric. Update, 10(1) : 48-51.

Author for correspondence :

\section{B.C. BOCHALYA}

Krishi Vigyan Kendra, (J.A.U.) Nana-Kandhasar, Chotila, SURENDRANAGAR (GUJARAT) INDIA Email: jat_bcb@yahoo.com See end of the article for authors' affiliations 